International Journal of Current Advanced Research

ISSN: O: 2319-6475, ISSN: P: 2319 - 6505, Impact Factor: SJIF: 5.995

Available Online at www.journalijcar.org

Volume 6; Issue 3; March 2017; Page No. 2829-2830

DOI: http://dx.doi.org/10.24327/ijcar.2017.2830.0118

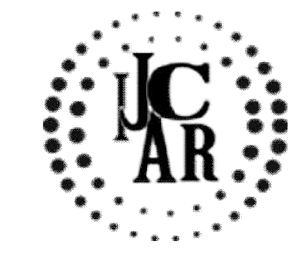

Research Article

\title{
CONSUMPTION OF SWEETS IN CHILDREN BELOW 6 YEARS OF AGE RELATED TO DENTAL CARIES IN RURAL AREAS
}

\author{
V.Nancy Selva Mary., Dhanraj and Ashok
}

Saveetha Dental College, Chennai

\section{A R T I C L E I N F O}

\section{Article History:}

Received $8^{\text {th }}$ December, 2016

Received in revised form $16^{\text {th }}$ January, 2017

Accepted $26^{\text {th }}$ February, 2017

Published online $28^{\text {th }}$ March, 2017

\section{Key words:}

Dental Caries, Rural Areas

\begin{abstract}
A B S T R A C T
Aim: To investigate the rate of consumption of sweets in children below 6 years of age related to dental caries in rural areas .

Method: This study was carried out in pandur village 15 kilometeres away from thiruvallur. The survey was carried out by a school children out at panchayat school.130 students screened for caries. The questionnaire included 20 questions that data from the questionnaire were extracted and analysed

Result :This study observed a market proportion of children consuming sweets having a significant prevalence of dental caries. In oral health awarness program the choice of sweet consumption and caries needs to be initiated further.
\end{abstract}

Copyright $\bigcirc 2017$ V.Nancy Selva Mary., Dhanraj and Ashok. This is an open access article distributed under the Creative Commons Attribution License, which permits unrestricted use, distribution, and reproduction in any medium, provided the original work is properly cited.

\section{INTRODUCTION}

The role of sugar as a risk factor in the initiation and progression of Dental caries is overwhelming. [1] Whether this initial Demineralization proceeds to clinically detectable caries or whether the lesin is remineralized by plaque minerals depends on a number of factors of which the amount and frequency of further sugars consumption are of utmost importance. Dental caries is significant yet a preventable public health problem. [3] It is the most common chronic disease of childhood that interferes with normal nutrition intake, speech, self-esteem and daily routine activities, because the caries pain adversely affects the normal food intake.

This results in underweight children with abnormal cognitive development. [2] A decade ago, World Health Organisation (WHO) published a review of global oral health status, which emphasized that despite great improvements in oral health in several countries, problems still persist. This is common among underprivileged populations in both developing and developed countries.A common perception is that dental caries rates are decreasing in developed countries but the trend in developing countries is not clear. Caries prevalence varies greatly between and within countries, as well as within different strata of the population. Statistically speaking, dental caries does not rank among the more serious diseases

*Corresponding author: V.Nancy Selva Mary

Saveetha Dental College, chennai in Africa. On an individual level, however, dental caries causes great suffering, pains and burden.It is crucial to control the disease process by assessing rendering the treatment required along with spreading awareness regarding prevention. Several prevalence studies have been conducted and reported on different occasions on the dental caries and treatment needs in developing countries such as India. The purpose of this study was to find the prevalence of dental caries in the rural areas of Thiruvallur district.

\section{MATERIALS AND METHODS}

130 students aged from 1-6 were randomly selected from the Rural area of Pandur, Kaivandur, Siruvanur of Thiruvallur District. The survey was carried out by a school children out of panchayat school. The Students screened for caries. The questionnaire included 20 questions that data from the questionnaire were extracted and analysed.

\section{RESULTS AND DISCUSSION}

The result shows that $83 \%$ children consume sweets below 6 years and $17 \%$ are not consuming. $7 \%$ of children take once a day $47 \%$ takes twice a day. $13 \%$ children like milk Chocolates and $36 \%$ like local Chocolates. $70 \%$ children are affected by dental caries (DMFT) (3.39) and 30\% of them are not affected $67 \%$ children are brushing twice a day $43 \%$ are brushing once a day. $93 \%$ of children are not brushing their tooth after consuming sweets $7 \%$ brush their tooth after consuming sweets. The higher prevalence of carries among the total population Indicates enomity of oral health problems in the rural areas of Thiruvallur District. The higher consumption of sweets and prevalence of caries among the 
age groups 0-6 indicates the poor oral healthy hygiene, poor oral health awareness among the populations. Although infants and young children typically select the most intimatesweet taste.

\section{consume sweets}

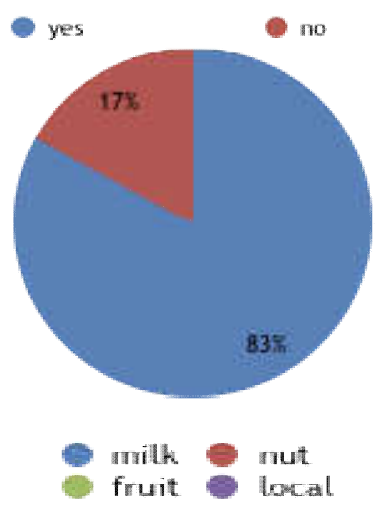

\section{chocolates}

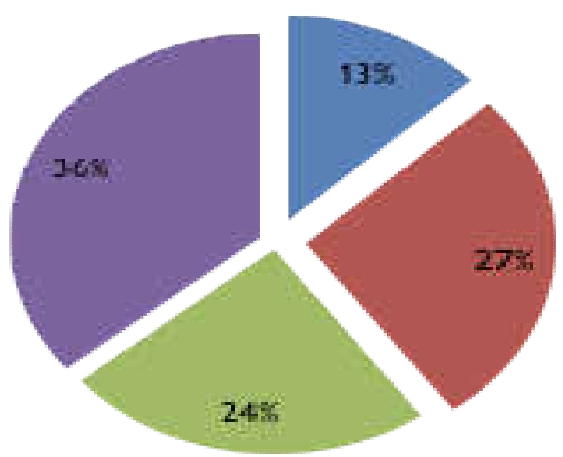

\section{Buying choclates}

once a day 0 twice a day $\odot$ thrice a day

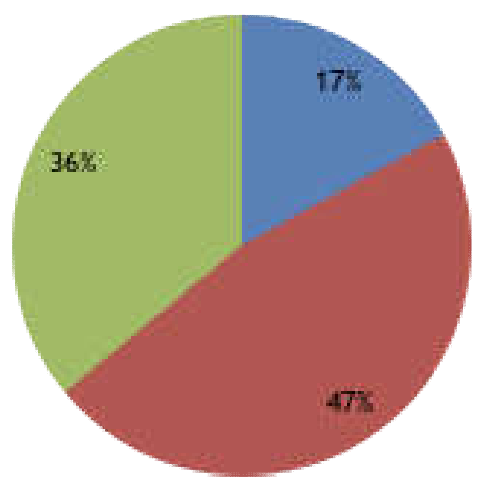

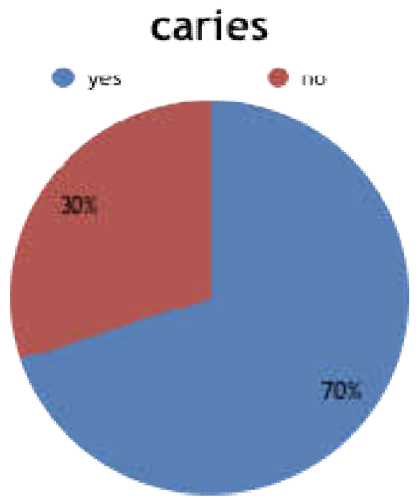

\section{CONCLUSION}

Human desire for sweets taste spans all ages races and cultures. Throughout evolution sweetness has had a role in human nutrition and also play a main role in developing caries in human especially in children. So for accessing dental carries prevalence as well as dental treatment needs among the people. So, the study is conducted to examine the same in the Rural areas of ThiruvallurGenerally the result in the Rural areas will be different when compared to the Urban and SubUrban areas. Consumption of sweets in children below 6 years in age is different from the other group conclusion. This study observed the market proportion of children consuming sweets having a significant prevalence of dental caries. In oral health awareness program the choice of sweet consumption and caries needs to be initiated further

\section{Reference}

1. Popkin BM, Nielsen S. The sweetening of the world diet. obes Res 2003,11, 1325-32 (pubmed)

2. Drewnowski A, Bellisle $\mathrm{F}$ is sweetness Addictive 2007; 32 suppl ; 52-60

3. Araujo GC \& Wong EH (2005) High risk drinking and college students' self-perceptions. Psychol Rep 97, 936-944.

4. BurrTogo P, Osler M, Sorensen TI \&Heitmann BL (2001) Food intake patterns and body mass index in observational studies. Int $J$ ObesRelatMetabDisord $25,1741-1$

5. Owsa \& Cooper M (2002) Possible risk factors in the development of eating disorders in overweight preadolescent girls. Int $J$ ObesRelatMetabDisord26, 1268-1273.

\section{Please cite this article in press as:}

V.Nancy Selva Mary., Dhanraj and Ashok (2017), 'Consumption of sweets in children below 6 years of age related to dental caries in rural areas', International Journal of Current Advanced Research, 6(3), pp. 2829-2830.

http://dx.doi.org/10.24327/ijcar.2017.2830.0118 